\title{
O LUGAR DA EDUCAÇÃO NA CULTURA DIGITAL: ESBOÇOS DE CRIANÇAS EJOVENS DIGITAIS
}

Sandro Bortolazzo ${ }^{1}$

Resumo: este artigo desenvolve uma análise sobre o lugar da educação diante da emergência da Cultura Digital. Assim, o estudo contempla dois movimentos: uma discussão sobre a ideia de crianças e jovens enquanto experts tecnológicos; uma reflexão sobre como a cultura digital tem promovido outras formas de compreender a educação. $\mathrm{O}$ estudo adota a pesquisa bibliográfica como ferramenta analítica a partir do levantamento de referências teóricas publicadas por meios escritos e eletrônicos. O referencial teórico compôs-se de autores que discutem aspectos sobre cultura digital e suas interfaces com a educação. Os achados da análise revelam que a cultura digital apresenta um desafio que vai além das habilidades ou mesmo do entrelaçamento de elementos tecnológicos à educação, mas dos modos como se fomentam formas culturais afinadas a um regime tecnológico.

Palavras-chave: Cultura Digital; Tecnologias Digitais; Educação; Crianças e Jovens.

\section{THE PLACE OF EDUCATION IN THE DIGITAL CULTURE: SKETCHES OF DIGITAL YOUTH AND CHILDREN}

\begin{abstract}
This article develops an analysis regarding the place of education based on the emergence of Digital Culture. Thus, the study contemplates two movements: a discussion about the idea of children and young people as technological experts; a reflection on how digital culture has promoted other ways of understanding education. The study adopts bibliographic research as an analytical tool based on written and electronic published theoretical references. The theoretical reference was made up of authors who discuss aspects about digital culture and its interfaces with education. The analysis findings reveal that the digital culture presents a challenge that goes beyond the skills or even the interweaving of technological elements to education, but on the ways in which cultural forms are tuned to a technological regime.
\end{abstract}

Keywords: Digital Culture; Digital Technologies; Education; Children and Young.

\section{INTRODUÇÃO}

O leitor sem dúvida já ouviu falar nas crises de abstinência que acometem as pessoas, jovens ou não, viciadas em outros tipos de drogas, e por isso talvez seja capaz de mentalizar a angústia desses adolescentes quando um vírus (os pais, os professores) lhes bloqueia o acesso à internet ou desliga seus celulares (BAUMAN, 2011, p.14).

' Pós- Doutorando no Institute for Culture and Society - University of Western Sydney.

$$
\begin{array}{lll}
\text { v. } 20 \text { n. } 44 \text { p. } 27-44 \quad \text { set } / \text { dez. } 2018
\end{array}
$$


Em 44 cartas do mundo líquido moderno, Bauman (2011) traça uma breve análise sobre a importância dos artefatos digitais no cotidiano dos jovens. Nos últimos 20 anos, a ideia de crianças e jovens enquanto experts tecnológicos tem se propagado nos meios de comunicação, no debate acadêmico. Assim, os modos como uma parcela significativa da população vêm se relacionando com os artefatos digitais a exemplo de smartphones, tablets, entre outros, permite vislumbrar transformações culturais, econômicas e, inclusive, pedagógicas.

É recorrente encontrar em revistas e jornais, nos programas de televisão e anúncios publicitários, um variado número de expressões indicando a naturalização da relação dos jovens com as tecnologias. Geração Digital, Geração Facebook, Nativos Digitais, Geração Y, Z, Geração Google, e assim por diante, são exemplos que sublinham a destreza dos mais jovens em operar aparatos tecnológicos para as mais diversas finalidades - entretenimento, aprendizagem, informação, consumo, participação em redes de sociabilidade. (BORTOLAZZO, 2015)

Os artefatos digitais são elementos presentes no cotidiano de muitas crianças e jovens contemporâneos, sendo que parte desta população ingressa nos espaços escolares previamente munida do conhecimento e das habilidades tecnológicas. Isso é resultado da precocidade com que ocorrem as primeiras interações tecnológicas, fato despontado nos recentes estudos sobre alfabetização, aprendizagem, ensino, etc.

Dessa forma, neste artigo é desenvolvido um estudo sobre o lugar da educação diante da emergência de uma Cultura Digital operando nos distintos espaços de sociabilidade. Questiona-se a naturalização da ideia de crianças e jovens como especialistas tecnológicos, e propõe-se uma reflexão da cultura digital enquanto fomento a outras formas de compreender a educação.

\section{ESBOÇANDO OS DIGITAIS: A EXPERTISE TECNOLÓGICA}

As tecnologias digitais operam numa variedade de espaços e dialogam, interagem, intervém, monitoram, executam e auxiliam muitas das atividades cotidianas. Pagamento de boletos bancários, acesso às notícias e informações, comunicação instantânea entre familiares e também nos ambientes profissionais, trabalhos acadêmicos, dentre inúmeras outras tarefas têm se apoiado nas facilidades promovidas pelos avanços tecnológicos. 
Mesmo que as tecnologias tenham adentrado os mais variados espaços, esta análise está se referindo a uma parcela da população jovem - atrelada, na maioria das vezes, aos grandes centros urbanos - que possui acesso e usufrui dos aparatos tecnológicos. Quer dizer, não se trata aqui de uma infância e juventude off-line, apartada tecnologicamente, desconectada, desplugada. Ao contrário, é uma juventude e infância hiperrealizada, para usar uma expressão de Narodowsky (2013).

Crianças conectadas 24 horas aos mais diversos dispositivos a que tem acesso: smarthpones, tablets, smartTV, consoles de videogames, só para mencionar alguns. Crianças digitais que não conseguem imaginar um mundo em que a informação e o mundo em si não estejam ao alcance da mão através da Internet. Crianças que vivem no imediatismo absoluto, na realização imediata do desejo (NARODOWSKY, 2013, p.25).

Seguindo a visão autor, não há uma referência somente ao acesso à internet, mas igualmente a todas as possibilidades de acessar os distintos dispositivos tecnológicos que permitem adquirir as ferramentas necessárias para a vida moderna.

$\mathrm{Na}$ contramão dessa perspectiva, o relatório da UNICEF intitulado Situação Mundial da Infância 2017: as crianças em um mundo digital, aponta que o acesso às tecnologias é um forte indicador de desigualdade, alertando que a própria lacuna de acesso à internet por parte de crianças e jovens estaria afetando a educação e a entrada no mercado de trabalho. De acordo com o relatório, em nível global, 29\% dos jovens entre 15 e 24 anos (346 milhões de pessoas) não têm acesso à internet. No continente africano esse dado se acentua, alcançando $60 \%$ dos jovens sem conexão à internet.

No Brasil, embora a situação não seja considerada ideal, os números mostram avanço. Dados do IBGE (Instituto Brasileiro de Geografia e Estatística) apontam que o número de usuários de internet no Brasil aumentou em 10 milhões entre 2009 e 2011. Desses usuários, 70\% são jovens com idade entre 15 e 19 anos. Segundo o Instituto, cresce também o número de jovens entre 10 e 17 anos que possuem aparelhos celulares e, na faixa etária que vai dos 10 aos 14 anos, o crescimento foi de 12,6\%. Outro estudo, esse desenvolvido em 12 países e divulgado pelo IBOPE Nielsen Online, revela que as crianças brasileiras são as que mais acessam a internet. Os internautas brasileiros com idade entre dois e 11 anos permanecem conectados, em média, 17 horas por semana. Esse dado posiciona os jovens brasileiros acima da média 
observada em países como França e Estados Unidos, onde os índices alcançaram 16 e 16,5 horas semanais respectivamente.

É fato que muitas das escolas ainda não incorporaram os elementos e recursos das tecnologias digitais, no entanto, o mesmo não pode ser dito em relação às crianças e jovens. A infância e juventude contemporâneas se encontram inundadas e, não raro, sendo definidas a partir das relações que mantém com as tecnologias de base digital.

Antes de prosseguir, é importante destacar como os conceitos de infância e juventude apresentam certo borramento, para além das fronteiras biológicas ou etárias. Ainda assim, tais conceituações não estão desvinculadas das divisões, repetidas vezes marcadas nas pesquisas no campo das ciências sociais, que se arriscam a definir o que são crianças ou jovens. Essas aferições acarretam uma série de discordâncias quanto aos parâmetros históricos e biológicos. Pode-se inferir que infância e juventude são parte de uma construção em contextos sociais específicos.

Segundo Dayrell (2003), a juventude não pode mais ser analisada a partir de critérios rígidos, como uma etapa com início e fim predeterminado. Na visão autor, a juventude é parte de uma condição social, mas também fruto de representação e, por isso, tem sido muito variada a maneira como cada sociedade (ou mesmo grupo social) lida com os jovens. A premissa vale igualmente para a categoria de infância, que não pode ser determinada simplesmente pela idade biológica ou faixa etária. Para Buckingham (2007), infância não é algo que tenha um sentido fixo. "Ao contrário, a infância é variável - histórica, cultural e socialmente variável. As crianças são vistas - e veem a si mesmas - de formas muito diversas em diferentes períodos históricos, em diferentes culturas e em diferentes grupos sociais” (idem, p.10).

Não se está querendo sugerir que os indivíduos biológicos a quem
podemos coletivamente concordar em chamar de "crianças" de
algum modo não existam, ou não possam ser descritos. O que se
pretende é dizer que tais definições coletivas são o resultado de
processos sociais e discursivos. Há nisso um certo grau de
circularidade. As crianças são definidas como uma categoria
particular, com características e limitações particulares, tanto por
si mesmas como pelos outros - pais, professores, pesquisadores,
políticos, planejadores, agências de bem-estar social e (claro) os
meios de comunicação. Essas definições são codificadas em leis e
políticas; e se materializam em formas particulares de práticas
sociais e institucionais, que por sua vez ajudam a produzir as
formas de comportamento vistas como tipicamente "infantis" - ao 
mesmo tempo em que geram formas de resistência a elas [grifo do autor] (BUCKINGHAM, 2007, p.10).

Embora muitas agências governamentais advoguem a utilização de demarcações etárias definidas, as pesquisas de caráter sociológico reclamam flexibilidade. Isso porque, além das categorias hoje serem mais elásticas e não darem conta de explicar alguns fenômenos do cotidiano, é preciso levar em consideração as transformações mais recentes nas experiências dos sujeitos. Aqui a própria relação com as tecnologias digitais é um forte indicativo dessas outras e novas experiências.

De um lado estão os que argumentam que as fronteiras entre as crianças, os jovens e os adultos estão desaparecendo, e que as tecnologias seriam as principais aliadas neste processo. Do outro lado estão os que alegam existir um crescente abismo entre as gerações em virtude do uso das tecnologias, ou seja, as experiências das crianças e dos jovens com os aparatos digitais estariam cavando um verdadeiro fosso entre pais e filhos, entre professores e alunos.

Esboçar crianças e jovens enquanto sujeitos imersos na cultura digital é uma forma de instituir e nomear uma parcela da população que vem compartilhando características comuns - engendradas pelo uso e consumo intenso de smartphones, tablets, computadores e pelas inúmeras formas de sociabilidade via internet -, agora muito menos atreladas a territórios físicos, tradições ou mesmo classes sociais, mas intensamente conectadas a produtos eletrônicos e redes sociais. Parte considerável dessas transformações se dá, na perspectiva de Bauman (2005), quando a vida social passa a ser cercada pelo mercado globalizado de imagens, produtos, estilos, modas, pelos sonhos e desejos materiais atravessados igualmente pelas ações midiáticas e por todos os sistemas comunicacionais.

Os elementos tecnológicos vêm sendo associados a crianças e jovens contemporâneos provavelmente porque eles já nasceram em um mundo cercado de tecnologia e possuem certa familiaridade e atração com os artefatos que vão surgindo diariamente. Grande parcela das crianças e jovens não somente se sentem atraídos pelas tecnologias, como as celebram, consomem e usam o tempo todo.

No entanto, é preciso ressaltar que nascer em um mundo capitaneado pelas tecnologias, muitas vezes, não enquadra crianças e jovens enquanto sujeitos da cultura digital, haja vista que os efeitos das tecnologias não são 
onipresentes, ou seja, nem todos têm a oportunidade de usufruir das benesses tecnológicas, e mesmo aqueles que tenham acesso podem, por sua vez, não se interessar. O impacto das tecnologias é sempre variável, não sendo ubíquo nem universal.

Crianças e jovens com acesso às tecnologias têm dedicado boa parte do dia em operar videogames, computadores, smartphones e tablets. Eles, de fato, formam a primeira geração mergulhada nas tecnologias, utilizando-as desde o berço. Câmeras de monitoramento estão lá para garantir o sono dos bebês; aplicativos para dispositivos móveis e filmes animados atuam como "babás" do século XXI, divertindo os filhos e garantindo sossego aos pais; numa idade mais avançada chegam jogos de videogame, ou seja, desde cedo se encontram imersos no universo das tecnologias. Deste modo, talvez seja difícil desvencilhar o uso e consumo de artefatos digitais quando essa parcela da população jovem ingressa nos espaços escolares.

O aprendizado sobre o mundo, a comunicação com os amigos e familiares, bem como os deveres escolares, muitas vezes, dependem do uso de computadores ou outros aparatos. O celular, por exemplo, virou acessório indispensável. Antes considerado objeto do mundo corporativo, útil à vida dos executivos, na atualidade sua popularização é inconteste e cada vez mais indispensável à vida dos sujeitos, sejam eles crianças, jovens ou adultos. As versões smartphones dos telefones celulares estão amplamente disponíveis e, para utilizar uma expressão de Lemos (2007), são uma espécie de "tele tudo", "um dispositivo que é ao mesmo tempo telefone, máquina fotográfica, televisão, cinema, receptor de informações jornalísticas, difusor de e-mails e SMS (...), GPS, tocador de música (MP3 e outros formatos), carteira eletrônica (...)” (idem, p.9).

Por se encontrarem integrados ao mundo tecnológico, as atividades cotidianas de crianças e jovens são expostas como dependentes das tecnologias. Tais alegações se encontram fundamentadas em um emergente corpo de evidências científicas, a exemplo dos experts como neurocientistas, psicólogos, pedagogos, entre outros profissionais.

Rose (1991) utiliza o termo "expertise" para se referir a um tipo particular de autoridade social, caracteristicamente inserida ao redor de problemas e situações e que, de alguma forma, confere diagnósticos alicerçados em certa pretensão de verdade. Segundo Rose (1991), as expertises amalgamam saberes e técnicas de diferentes áreas, formando um conjunto de conhecimentos, que não derivam de apenas uma única teoria ou campo do saber, mas que se encontram 
unificados dentro do que poderíamos chamar de prática pedagógica. Essas expertises, por sua vez, estão integradas em diversas práticas difundidas em materiais institucionais, políticos, pedagógicos, midiáticos e de entretenimento: cursos, livros, jogos, reportagens de revistas e jornais, programas televisivos, leis, diretrizes, etc.

Assim, uma série de características - fluência tecnológica, alfabetizados na linguagem digital, aptos a operar facilmente computadores - associadas a crianças e jovens tem mostrado a relação das tecnologias digitais como um elemento intensamente presente, desejado e, por isso, também, aceito.

Importa destacar o quanto especialistas da Educação, Medicina, Administração, Marketing, Psicologia, Sociologia, vêm sendo acionados a falar sobre a relação dos jovens com as tecnologias, constituindo discursos que prescrevem regras de conduta e regulamentação. Para Rose (1998), os grupos especializados de profissionais vão se dedicando a nomear, descrever, classificar e instituir novos saberes que se encontram implicados em produzir conhecimento sobre os sujeitos e instituir modos de ser sujeito na contemporaneidade.

Os saberes especializados mais do que apenas identificar os comportamentos e atributos de crianças e jovens digitais, invariavelmente, fornecem uma série de orientações para as condutas de pais, professores, etc. Há espraiado um discurso - aquilo que a analítica de Foucault (1998) procurou mostrar como um conjunto de conhecimentos construídos em um determinado contexto histórico e em conformidade com certas regras e domínios de poder implícito de que, em virtude do conhecimento proporcionado pelas tecnologias digitais, o acesso às informações tem permitido que os jovens desempenhem um papel mais ativo enquanto produtores da cultura da atualidade - criando músicas, manipulando imagens, interagindo nas redes sociais, editando vídeos. No entanto, é difícil precisar se esses jovens seriam mais imaginativos, inteligentes ou mesmo mais felizes que as do passado, mas certamente parecem ser os mais sintonizados com a cultura do seu tempo, essa transformada e formatada, muitas vezes, com o auxílio das tecnologias. 


\section{CONECTADOS: O LUGAR DA EDUCAÇÃO NA CULTURA DIGITAL}

As expressões "novas tecnologias de informação e comunicação" (TICs), "mídia digital", "cultural digital" - entres outros termos que conectam meios de comunicação, mídia, sociedade e tecnologia - têm sido associadas a certa visão, na maioria das vezes, positiva, do futuro. Juntos emergem igualmente a utopia da maior produtividade e das oportunidades e possibilidades educacionais.

De acordo com Lister et al. (2009), a expressão "novas mídias" reflete certa evolução dos meios de comunicação que, a partir dos anos 1980, começaram gradualmente se envolver em um contínuo de mudanças tecnológicas. Essas transformações, de forma alguma, se encontravam confinadas aos meios de comunicação, uma vez que alterações mais amplas de âmbitos social e cultural estavam sendo identificadas a partir de meados da década de 1960.

Alguns indicativos dessas mudanças, para Lister et al. (2009), aludem aos intensos processos de globalização e à substituição de uma era industrial de manufatura por uma era da informação. A emergência das novas mídias, na mesma direção, está incluída enquanto parte dessas variações. No entanto, como seria possível identificar alguma mudança substantiva que vá além dos novos meios de comunicação, ou seja, algo mais sensível que não se limite à discussão sobre as mudanças de contextos? É possível que resida aí a expressão "mídia digital", uma vez que leva em consideração um meio específico e suas implicações no armazenamento, consumo e distribuição de informações por meio de códigos binários.

Um sistema digital pode ser pensado como um conjunto de dispositivos de produção, transmissão e armazenamento de sinais. Em outras palavras, os sinais digitais, por exemplo, convertem a voz de locutores e apresentadores em uma série de números, 1 (uns) e 0 (zeros). É uma tecnologia que funciona por compressão de dados, permitindo o armazenamento de grande volume de informações em um pequeno dispositivo físico ou virtual. Outra característica é que as tecnologias digitais podem ser conectadas entre si para formar grandes redes que se espalham por longas distâncias.

Para Lister (2009), todos os métodos e as práticas sociais de comunicação, representação e expressão desenvolvidas a partir do digital e dos computadores 
em rede, são elementos de formação das mídias digitais, alterando, inclusive, outros meios: dos livros aos filmes, dos telefones aos televisores.

Assim, os sistemas digitais de comunicação poderiam ser pensados como os que se valem da digitalização com o objetivo de captar, transmitir e disseminar informações, sejam essas em formato de músicas, imagens, textos, vídeos, ou todos eles inter-relacionados. Por sua vez, é com a disseminação das mídias digitais que as discussões sobre o potencial desses novos meios de comunicação em transformar a vida em sociedade começam a se desenvolver.

Este é um período da história difícil de imaginar uma sociedade desprovida de computadores ou redes de telefonia. Os avanços tecnológicos são contínuos e velozes, como uma via de mão única, não havendo possibilidade de retrocesso. Os avanços de ordem econômica relacionados às tecnologias, principalmente àquelas dos aparatos conectados à internet, têm servido igualmente para moldar experiências. Embora essa diversidade de artefatos disponíveis e elementos digiais nos remetam a um universo repleto de novidades, sempre prontas a serem consumidas imediatamente e, logo depois, descartadas (os vídeos "virais" no YouTube são um exemplo exponencial), há uma clara preocupação com os usos das novas tecnologias. E uma questão importante a ser considerada é que as tecnologias digitais não são coadjuvantes às questões culturais, mas elementos centrais e onipresentes.

De fato, é difícil apreender, em toda a sua extensão, as transformações ocasionadas pelo digital nas sociedades contemporâneas. A maioria dos meios de comunicação - a televisão, o cinema, a indústria da música, as revistas - tem cada vez mais produzido e distribuído seus produtos em formato digital. No entanto, a tecnologia digital não se limita aos meios de comunicação. Nos ambientes de trabalho estamos cercados e, de certa forma, sendo vigiados pelo digital. Computadores com acesso à internet se transformaram em ferramentas indispensáveis a inúmeras atividades do cotidiano, envolvendo compras, entretenimento e lazer, informação, estudo. Nos supermercados, nos elevadores, nos escritórios, nas escolas, nas universidades e, muitas vezes, nas ruas, somos monitorados digitalmente. A digitalização dos sistemas bancários, os câmbios de moedas internacionais, a globalização financeira e todas as possibilidades de convergência e integração têm sido possibilitadas pela tecnologia digital. E quando uma série de invenções permitiu a conexão entre milhões de pessoas às redes de informações, de fato, as práticas sociais passaram também a incorporar alguns hábitos gerados pelo uso amplo das tecnologias digitais. 
A emergência de uma Cultura Digital estaria designando o termo digital a uma forma particular de vida de sujeitos em um determinado período da história. Invocando uma das definições de cultura proposta por Williams (1975), à cultura digital compete pensá-la como um marcador cultural, uma vez que envolveria tanto os artefatos quanto os sistemas de significação e comunicação que demarcam e distinguem nosso modo de vida contemporâneo.

A comunicação dominada pelas tecnologias digitais tornou possível a produção/emergência da Cultura Digital porque se trata de algo que envolve, e no qual se atua enquanto produtor, consumidor, e que, por isso, tem integrado a vida cotidiana, invadido os lares e interferido nas relações que se estabelecem com o mundo.

O debate sobre a própria Cultura Digital, por exemplo, se apoia na crença de que tal cultura representa uma decisiva ruptura com aquilo que a precedeu (no caso aqui a cultura analógica). Mesmo assim, analisar a Cultura Digital como um ente completamente novo, e seu desenvolvimento determinado tão somente pelos avanços tecnológicos, nos remeteria a uma visão, fundamentalmente, determinista. Seria mais adequado sugerir, então, que "a tecnologia digital é um produto da cultura digital, e não vice-versa” (GERE, 2008, p.17).

$\mathrm{O}$ digital não se refere apenas às possibilidades de uma determinada tecnologia, mas abrange formas de pensar e de desenvolver certas atividades que são incorporadas por essas tecnologias. Vale acrescentar ainda que um conceito associado à cultura digital permite articulações com outros tais como Cibercultura (LEVY, 1999), Era da informação ou Era Digital (CASTELLS, 1999). Cada um deles, descritos por antropólogos, sociólogos, filósofos, comunicadores, foram pensados para demarcar esta época em que as relações humanas têm sido fortemente mediadas por artefatos digitais.

Recorrer ao digital é evocar a todo um conjunto de manifestações que incluem simulacros virtuais, comunicações instantâneas, conectividade. É aludir a uma vasta gama de formas midiáticas, possibilitadas pela tecnologia digital, abrangendo a realidade virtual, o cinema digital, a televisão digital, a música eletrônica, os jogos de computador, a World Wide Web, a telefonia digital, e assim por diante. Também compreende o mundo dos negócios dominados por empresas de tecnologia como a Microsoft, a Apple, a Sony, entre outras.

A imersão dos sujeitos na Cultura Digital exige um tipo de educação que compreenda as dinâmicas sociais e que possa dialogar com a provisoriedade do 
contemporâneo. Assim, qual seria o espaço da educação diante da Cultura Digital?

O termo educação, muitas vezes, tem sido acionado no campo dos Estudos Culturais, para designar os processos de formação dos sujeitos que ocorrem para além da educação escolarizada ou mesmo do estabelecimento de políticas relacionadas às instituições escolares.

Cabe, contudo, esclarecer, que as análises dos Estudos Culturais em Educação têm procurado se voltar a um território de pesquisa, anteriormente negligenciado, qual seja, aquele que "questiona a produtividade da cultura nos processos educativos em curso nas sociedades de hoje"(WORTMANN, COSTA, SILVEIRA, 2015 p.34). Segundo as autoras, os Estudos Culturais em Educação ampliam o entendimento sobre as repercussões que instituições, temáticas, práticas, produções e artefatos têm sobre as sociedades e os sujeitos que nelas habitam. Além disso, problematizam, por exemplo, a produtividade de artefatos culturais tais como programas de televisão, jornais, revistas, sites de internet, entre outros, em educar, governar, conduzir as condutas dos sujeitos. Quer dizer, práticas educativas também se encontram para além dos muros escolares, igualmente sendo exercidas por jornais, programas de TV, filmes, revistas, entre outros artefatos presentes na vida contemporânea.

Outras formas de entendimento sobre os matizes da educação dentro dos Estudos Culturais são apresentados por Costa, Silveira e Sommer (2003, p.54):

Uma possibilidade é conceber os Estudos Culturais em Educação como um compartilhamento de entendimentos, de conceitoschave e "formas de olhar" que eles trouxeram, principalmente, para a área das humanidades, da comunicação, da literatura. Entretanto, isso soa um tanto parcial e inexato, uma vez que não se trata apenas de "partilhar", "apropriar-se" ou "utilizar"; as "lentes" dos EC parece que vêm possibilitando entender de forma diferente, mais ampla, mais complexa e plurifacetada a própria educação, os sujeitos que ela envolve, as fronteiras (p.54).

Assim, os autores vão expandindo o entendimento de educação, pedagogia e currículo para além dos muros escolares, desnaturalizando teorias e discursos instaurados no aparato escolar, dando visibilidade aos dispositivos 
disciplinares acionados dentro e fora das escolas e ampliando as discussões sobre diferença, identidade e processos de subjetivação ${ }^{2}$.

Os processos educativos, nos Estudos Culturais, podem ser vistos e pensados a partir dos inúmeros espaços, artefatos, mecanismos e procedimentos que vão instituindo certas práticas sociais e que, paulatinamente, produzem referências, saberes, sujeitos, concepções de mundo, e assim por diante. Os Estudos Culturais, nesta perspectiva, surgem como um campo intelectual dedicado a examinar outros espaços de produção de sujeitos e, por isso, também se encontram comprometidos em repensar a educação e as diversas manifestações culturais.

Na verdade, o fio central dos estudos culturais pode ser entendido como o estudo da cultura como prática significativa de representação. Também exige a investigação dos modos pelos quais os significados são produzidos em uma variedade de contextos. Além disso, as representações e os significados culturais apresentam certa materialidade. Ou seja, estão incorporados em sons, inscrições, objetos, imagens, livros, revistas e programas de televisão. Eles são produzidos, aprovados, utilizados e compreendidos a partir de um contexto social específico (BARKER, 2001, p. 8)

Considera-se, assim, que os artefatos da Cultura Digital são também elementos constitutivos na educação de crianças e jovens contemporâneos na medida em que ensinam determinadas formas de ver, de pensar e de agir sobre o mundo. O uso e consumo de smartphones e tablets, bem como todo o espectro de situações, objetos, práticas e relações que formam parte da Cultura Digital vão instigando valores, gerindo condutas e produzindo subjetividades.

O elemento digital, objetivado materialmente em dispositivos tais como computadores, permite um tipo de interação até pouco tempo novo para o campo da educação. A expressão Cultura Digital coloca um desafio epistemológico à educação e às ciências sociais de forma geral. Seria a Cultura Digital exclusivamente um tipo de cultura imersa dentro dos espaços de sociabilidade online, ou estaria ela atrelada a um conjunto de manifestações e

\footnotetext{
${ }^{2}$ Os processos de subjetivação são métodos que fazem com que o sujeito se torne aquilo que ele é. Refere-se às propriedades que caracterizam o ser humano como sujeito. $\mathrm{O}$ termo subjetividade carrega conotações de interioridade, de pessoalidade. Segundo Rose (2001), a subjetividade é o nome dado a todo o movimento de compor e recompor forças, relações e práticas na medida em que tenta transformar (ou opera para isso) o ser humano em sujeito.
} 
práticas culturais que se utilizam de artefatos digitais? A Cultura Digital não poderia ser pensada dentro do espectro das Teorias da Educação na medida em que se pode pensar o conceito de Educação como elástico suficiente para abarcar as interações e os processos mediados por tecnologias eletrônicas?

Uma reflexão sobre o lugar da educação na Cultura Digital parte da compreensão das transformações nas relações com o saber, que se encontram atravessadas pelo amplo acesso às informações, bem como pela apropriação de conhecimento por parte do mais jovens através dos aparatos digitais. Há, nesse sentido, um favorecimento de um tipo de educação personalizada, sob demanda, onipresente, quer dizer, não mais concebida apenas no espaço das salas de aula, mas do acesso a informações em qualquer lugar e a qualquer hora.

De forma geral, por conta de algumas habilidades específicas, os mais jovens são narrados enquanto experts digitais, como uma espécie de professor tecnológico. Mais do que isso, o constante uso das tecnologias digitais incita formas de comportamentos e vem produzindo determinados tipos de sujeitos. Esses cada vez mais afinados à paisagem tecnológica.

De fato, hoje é possível observar a associação das tecnologias a "uma educação digital" orientada a uma "educação do e para o futuro". A inserção das tecnologias nos ambientes escolares, além de constituir um discurso próprio, nos últimos anos, tem condicionado as práticas pedagógicas para que os recursos digitais sejam promovidos e utilizados nas salas de aula. O movimento de entrada dos aparatos tecnológicos na educação escolarizada tem produzido, inclusive, políticas, como no caso da distribuição pelo Ministério da Educação em $2012^{3}$ de tablets para professores da rede pública de ensino.

Junto à Buckingham (2010), é possível visualizar que boa parte dos planos de ação são caracterizados por uma forma de determinismo tecnológico, quer dizer, imaginar que a tecnologia digital automaticamente produzirá certos efeitos (por exemplo, em relação aos modos de aprendizagem ou a determinadas

\footnotetext{
${ }^{3}$ De acordo com dados do próprio Ministério da Educação (2013), depois das entregas dos aparelhos, abriuse um edital para o recebimento de propostas de aplicativos educativos para tablets, que tenham por objetivo enriquecer o currículo dos alunos, bem como contribuir para a formação continuada dos professores. Essa iniciativa, inclusive, permitiu que empresas privadas adentrasse o mercado educacional de aplicativos unindose ao sistema público de ensino. Além disso, é importante ressaltar que houve diversos atrasos nas entregas do tablets, sendo que muitos professores são foram contemplados pela iniciativa já que a mesma previa o pedido e acompanhamento por parte dos estados e municípios.
} 
formas de cognição) sem restrição dos contextos sociais em que seja usada, nem mesmo dos atores sociais que a usem.

A ideia de que a tecnologia transformaria a educação é uma ilusão. A educação escolarizada provavelmente continue servindo a muitas funções econômicas, sociais, políticas. O que se pode depreender desse debate é que, talvez, os interesses estejam mudando rapidamente e constantemente e, por isso, certa maneira de conduzir as vidas por parte dos mais jovens tem sido representado como incompatível aos sistemas formais de educação.

Nesse debate, Buckingham (2007) tem sido um dos autores que levanta muitas questões sobre a presença tecnológica nos espaços escolares. Para o autor, algumas noções que circundam a Geração Eletrônica (termo utilizado por ele) se apoiam em certo determinismo tecnológico, sem a crítica necessária às generalizações produzidas pelos especialistas. Quer dizer, não é somente em função do uso de computadores, tablets e smartphones que essa geração vem ganhando visibilidade, mas também por conta de certas condições econômicas e culturais que possibilitaram que as tecnologias digitais se tornassem visíveis e adentrassem os diversos espaços de sociabilidade. Nos últimos 50 anos, por exemplo, o tempo de lazer das crianças e dos jovens foi sendo privatizado. Segundo Buckingham (2007), o lugar de lazer foi deslocado dos espaços públicos, como as ruas e as praças, para os espaços mais privados, como o das casas. Assim,

a ansiedade sobre 'o perigo dos estranhos', o tráfego e outras ameaças às crianças encorajaram pais e mães a equipar o lar (e em particular o quarto das crianças) como um local de diversão, uma alternativa tecnologicamente rica aos riscos potenciais do mundo exterior [grifo do autor] (BUCKINGHAM, 2007, p. 47).

Por sua vez, o aparelhamento tecnológico só foi possível devido ao aumento generalizado da renda, à redução do tamanho médio das famílias, entre outros fatores. Isso significa que, ao longo das últimas décadas, houve um investimento econômico e cultural que permitiu engajar os jovens com as tecnologias, sendo possível notar os inúmeros fenômenos capitaneados por eles, como o intenso e renovado consumo de aparelhos celulares e a expansão e popularidade das redes sociais. No entanto, a alegação de que as tecnologias são incorporadas naturalmente pelos jovens é uma argumentação forjada e produzida na intervenção de várias áreas, da medicina à educação, da psicologia aos aparatos midiáticos. Concordo com Buckingham (2007) que grande parcela de crianças e jovens não sabem operar computadores e videogames. Muitas 
vezes, assim como os adultos, experimentam sentimentos de inaptidão, desinteresse e frustração. "Em geral, essa vivência tecnológica tem sido experimentada por poucos e os benefícios criativos, educacionais e comunicativos dessas tecnologias são apenas percebidos por uma pequena elite” (BUCKINGHAM, 2007, p. 39). Aliás, em alguns países, entre eles o Brasil, grande parcela da população jovem nem computador possui.

Papert (1980), considerado um dos grandes gurus tecnológicos, ainda na década de 1980, dizia que a invasão dos computadores transformaria completamente a educação. O processo educativo, segundo o autor, se tornaria praticamente redundante já que os computadores iriam proporcionar aos sujeitos o poder de determinar seus próprios caminhos e padrões de educação. De fato, o pressuposto de Palpert não se concretizou. A escola enquanto instituição permanece e aspectos de ensino e aprendizagem se mantem, apesar da influência tecnológica.

Outro aspecto para refletir sobre o espaço da Educação na Cultura Digital é pensar que não se requer mais tanto a dependência de recursos fixos tais como computadores, laboratórios de informática, bibliotecas ou mesmo professores. A colaboração e produção coletiva de conteúdo, que acontece em redes sociais, blogs, tendo como exemplo expoente a enciclopédia online Wikipédia, tem permitido olhar para educação a partir da ótica digital, seja buscando suas especificidades, seja procurando compreendê-las na relação com as redes interpessoais. É possível ainda adicionar que, em pleno século XXI, está em movimento um tipo de educação ubíqua. Quer dizer, a ampliação das formas de conexão entre homens e homens, máquinas e homens, e máquinas e máquinas, motivadas pelo nomadismo da cultura contemporânea e pelo desenvolvimento da computação ubíqua - 3G, 4G, bluetooh, e assim por diante - permite com que a era da conexão transforme a educação em um processo globalizado e generalizado, envolvendo o usuário em plena mobilidade.

\section{CONSIDERAÇÕES}

De fato, a escola enquanto instituição não vai desaparecer. No entanto, uma das questões centrais é que, nos últimos 50 anos, houve uma relativa aceleração no desenvolvimento das tecnologias enquanto marcas de tempo, consideradas, igualmente, um dos principais fatores de reconfiguração da sociedade. No cerne das transformações engendradas na virada do século, 
podemos perceber que o avanço do capitalismo segue amparado por uma sempre emergente cultura tecnológica.

Crianças e jovens vêm sendo instituídos pelo uso ilimitado que imprimem às tecnologias digitais. Ilimitado no sentido de conduzir seus relacionamentos pessoais e profissionais, seus modos de aprendizagem e estilos de vida, suas práticas de entretenimento e lazer. Isso porque, de alguma forma, os computadores portáteis, as relações e recursos online e os dispositivos móveis de comunicação como telefones celulares ensejam outras sociabilidades e, por assim dizer, outras formas e modelos de educação.

Dessa maneira, a Cultura Digital vem instaurando formas fluídas e móveis de educação, assim como outros modos de habitar o contemporâneo. Trata-se de um tipo de cultura compatível com uma sociedade que demanda flexibilidade e mobilidade. Os aplicativos para telefones celulares e tablets, por exemplo, são produtos para serem carregáveis e de fácil acesso. $\mathrm{O}$ consumo desse tipo de tecnologia se ajusta aos modos de vida flexíveis e se afina a uma espécie de mobilidade contínua. Além disso, as funcionalidades carregadas por esses aparatos representam parte dos elementos presentes no cotidiano dos sujeitos que vivem sob a tutela da Cultura Digital.

É dentro dessa matriz de inteligibilidade que o espaço da educação na Cultura Digital pode ser vislumbrado, ou seja, um tipo de educação não centrada simplesmente na utilidade e usabilidade de hardware, software, mas pensada sob uma perspectiva ampliada, aquela das telas dos telefones celulares, dos aplicativos, da convergência, da integração das linguagens, mas sobretudo das formas como tais mecanismos digitais têm instituído modos de viver, de se relacionar, de aprender.

\section{REFERÊNCIAS}

BARKER, Chris; GALASINNSKI, Dariusz. Cultural Studies and Discourse Analysis: a Dialogue on Language and Identity. London: Sage Publications, 2001.

BAUMAN, Zygmunt. Identidade: entrevista a Benedetto Vecchi. Trad. Carlos Alberto Medeiros. Rio de Janeiro: Zahar, 2005.

BAUMAN, Zygmunt. 44 Cartas do Mundo Líquido Moderno. Trad. Vera Pereira. Rio de Janeiro: Zahar, 2011. 
BRASIL. Ministério do Planejamento, Orçamento e Gestão. Instituto Brasileiro de Geografia e Estatística. Acesso à Internet. Disponível em: <http://www.ibge.gov.br/home/estatistica/populacao/acessoainternet/> Acesso em: 19 de Julho de 2018.

BORTOLAZZO, Sandro Faccin. Narrativas acadêmicas e midiáticas produzindo uma Geração Digital. Porto Alegre, 2015. 206 f. Tese. (Doutorado em Educação) - Programa de Pós- Graduação em Educação, Universidade Federal do Rio Grande do Sul. Porto Alegre, 2015.

BUCKINGHAM, David. Crescer na Era das Mídias Eletrônicas. Trad. Gilka Girardello e Isabel Orofino. Rio de Janeiro: Loyola, 2007.

BUCKINGHAM, David. Cultura Digital, Educação Midiática e o Lugar da Escolarização. Educação \& Realidade. Porto Alegre, Vol.35 n.3, set - dez 2010.

CASTELLS, Manuel. A Sociedade em Rede, v. 1. Trad. Roneide Venâncio e Jussara Simões. São Paulo: Paz e Terra, 1999.

COSTA, Marisa Vorraber; SILVEIRA, Rosa M. Hessel.; SOMMER, Luís Hen rique. Estudos Culturais, educação e pedagogia. Revista Brasileira de Educação. Campinas, no 23, p. 36-61, maio/jun./jul./ago 2003.

DAYRELL, Juarez. O jovem como sujeito social. Revista Brasileira de Educação. Rio de Janeiro: n. 24, 2003, p. 40 - 53.

FOUCAULT, Michel. A ordem do discurso: aula inaugural no Collège de France, pronunciada em 2 de dezembro de 1970. Trad. Laura F. A. Sampaio. Campinas: Loyola, 1998.

GERE, Richard. Digital Culture. London: Reaktion Books, 2008.

IBOPE Nielsen Online: Instituto Brasileiro de Opinião Pública e Estatística. Audiência de Internet. Disponível em:< http://www.ibope.com.br/pt-br/noticias/paginas/criancas-brasileiras-sao-asque-ficam-mais-tempo-conectadas-a-internet.aspx > Acesso em $18 \mathrm{Jul}$. 2018.

LEMOS, André. Cidade e Mobilidade.Telefones Celulares, funções pósmassivas e territórios informacionais. Revista do Programa de Pós-Graduação em Ciências da Comunicação, USP, ano 1, n.1, São Paulo, 2007. 
LÉVY, Pierre. Cibercultura. Trad. Carlos Irineu da Costa. São Paulo: Editora 34, 1999.

LISTER, Martin; DOVEY, Jon; GIDDINGS, Seth; GRANT, Iain; KELLY, Kieran. New Media: a critical introduction. 2. ed. New York: Routledge, 2009.

NARODOWSKI, Mariano. Hacia un mundo sin adultos. Infancias híper y desrealizadas en la era de los derechos del niño. Actualidades Pedagógicas. N. 62, 2013, p. $15-36$.

PAPERT, Seymour. Mindstorms: Children, Computers and Powerful Ideas. New York: Basic Books, 1980.

ROSE, Nikolas. Experts of the Soul. Psychologie und Geschichte. 1991, p. 9199.

ROSE, Nikolas. Governando a alma: a formação do eu privado. In: SILVA, Tomaz. T. (Org.) Liberdades Reguladas. Petrópolis: Vozes, 1998.

UNICEF Brasil. Situação Mundial da Infância 2017: as crianças em um mundo digital. Disponível em:

<https://www.unicef.org/brazil/pt/media_37643.html>.Acesso em 18 Jul. 2018.

WILLIAMS, Raymond. Technology and Cultural Form. $1^{\circ}$ ed. Londres: Shocker Books, 1975.

WORTMANN, Maria Lúcia; COSTA, Marisa Vorraber; SILVEIRA, Rosa Hessel. Sobre a emergência e a expansão dos Estudos Culturais em Educação no Brasil. Educação, PUCRS, Porto Alegre, v. 38, n. 1, jan./abr. 2015 p.32-48.

Recebido em 28 de maio de 2018. Aprovado em 21 de agosto de 2018. 